\title{
CXCIX.-Studies in Emulsions. Part III. Further Investigations on the Reversal of Type by Electrolytes.
}

\section{By Shanti Swarupa Bhatnagar.}

IN a previous paper of this series (this vol., p. 61), the effects of a large number of electrolytes on the reversal of phases in emulsions prepared with univalent soaps have been described. A complete quantitative investigation on the effects of electrolytes on emulsion equilibrium being of fundamental importance for the elucidation of the mechanism of emulsification, attempts were made to examine whether emulsions prepared with the so-called insoluble emulsifiers of Pickering could undergo a reversal of type under the influence of electrolytes. The effects of volume ratio of the phases and temperature were minimised by carrying out the experiments at about $17-19^{\circ}$ and by adding a moderate amount of the emulsifying agent to equal volumes of the two phases. It has been shown that under these conditions (Clayton, "Margarine Manufacture"; Bhatnagar, T., 1920, 117, 542) the type of emulsion obtained is mainly dependent on the nature of the emulsifying agent. The emulsions were prepared in the manner described in previous papers (loc. cit.), and were examined by the drop method of Briggs and confirmed by the electrical method (loc. cit.) and under the microscope.

\section{EXPERI M E T A L.}

Finely-divided solids like basic salts of copper and nickel were first used by Pickering (T., 1907, 91, 2002) in preparing concentrated emulsions. No attempts seem to have been made by him or any other investigator in the field to examine whether a reversal of type can be brought about in emulsions prepared in that fashion. Earlier attempts with ordinary, finely-powdered hydroxides of zinc, cadmium, and aluminium brought out nothing new. Later, it was considered desirable to prepare fresh samples of zinc hydroxide for use as emulsifying agent. In order to do so, about 6 grams of pure zinc sulphate were dissolved in about 200 c.c. of water and an excess of potassium hydroxide solution was added, so that all the zine hydroxide precipitated was dissolved. Small quantities of dilute hydrochloric acid were then slowly added until the precipitate just reappeared. Such a solution, when kept for some time, threw down a moderately large quantity of zinc hydroxide as 
BHATNAGAR: STUDIES IN EMULSIONS. PART III. 1761

coagulum. The coagulum and liquid were transferred to a parchment dialyser and left there for five days. The water in the outer vessel was changed from time to time until no more alkali diffused out through the dialyser and the liquid became neutral to litmus. The coagulum was then made up to a litre and transferred to a carefully cleansed, resistance-glass flask. On agitating this suspension with B.P. paraffin or kerosene oil, it was possible to form stable emulsions sensitive to electrolytes, the emulsions prepared by using the alkali-free suspensions of zinc hydroxide forming the water-in-oil type of emulsion, as opposed to those prepared by alkaline zinc hydroxide, which formed the oil-in-water type. The zinc hydroxide coagulum formed by precipitation with ammonia gave similar results in dialysed and undialysed forms as long as the coagulum was kept moist. Dried zinc hydroxide was incapable of forming stable emulsions. Several samples of 20 c.c. of suspension, each of equal weight, were emulsified with 20 c.c. of oil. The quantity of zinc hydroxide in the aqueous phase was approximately $3 \cdot 2$ grams per litre in each case. The effects of various electrolytes were then examined on emulsions prepared by using this suspension alone and with various electrolytes, and some of these results are shown in Table $\mathbf{I}$.

\section{TABLe I.}

Zinc Hydroxide.

Amount of aqueous phase $=20$ c.c.

Amount of kerosene oil $=20$ c.e.

Quantity of zinc hydroxide $=3 \cdot 2$ grams per litre.

\begin{tabular}{|c|c|c|c|c|}
\hline \multicolumn{2}{|c|}{ Electrolyte. } & $\begin{array}{l}\text { Quantity in } \\
\text { gram-mols. } \\
\text { per cent. }\end{array}$ & $\begin{array}{l}\text { Type of } \\
\text { emulsion. }\end{array}$ & \multirow[t]{2}{*}{ Stability. } \\
\hline $\mathrm{KCl}$ & $\left\{\begin{array}{l}1 \\
2 \\
3\end{array}\right.$ & $\begin{array}{l}0.0005 \\
0.001 \\
0.005\end{array}$ & $\begin{array}{c}\mathrm{W} \text { in } \mathrm{O} \\
,, \\
,\end{array}$ & \\
\hline $\mathrm{K}_{2} \mathrm{SO}_{4}$ & $\left\{\begin{array}{l}1 \\
2 \\
3\end{array}\right.$ & $\begin{array}{l}0 \cdot 0005 \\
0.001 \\
0 \cdot 006\end{array}$ & ", & \multirow[t]{2}{*}{ All quite stable. } \\
\hline $\mathrm{Al}_{2}\left(\mathrm{SO}_{4}\right)_{3}$ & $\left\{\begin{array}{l}1 \\
2 \\
3\end{array}\right.$ & $\begin{array}{l}0 \cdot 0001 \\
0 \cdot 001 \\
0 \cdot 005\end{array}$ & ", & \\
\hline $\mathrm{K}_{3} \mathrm{PO}_{4}$ & $\left\{\begin{array}{l}1 \\
2 \\
3\end{array}\right.$ & $\begin{array}{l}0.001 \\
0.002 \\
0.003\end{array}$ & $\frac{",}{O \text { in } W}$ & \multirow[t]{2}{*}{ Separation into layers. } \\
\hline $\mathrm{KOH}$ & $\left\{\begin{array}{l}1 \\
2 \\
3\end{array}\right.$ & $\begin{array}{l}0 \cdot 001 \\
0 \cdot 0015 \\
0.002\end{array}$ & $\begin{array}{l}W \text { in } O \\
O \text { in } W \\
\text {, }\end{array}$ & \\
\hline $\mathrm{NaOH}$ & & $0 \cdot 002$ & , & \\
\hline
\end{tabular}


In order to obtain further results, coagula of lead oxide, lead carbonate, copper and aluminium hydroxides, casein, lecithin, rosin, and egg-albumin were prepared in a somewhat similar fashion, and some of them are described in detail later on.

\section{Lead Oxide.}

Preparation.-By precipitating the insoluble oxide by the action of the hydroxide on a solution of lead nitrate and dialysing the coagulum as in the case of zinc hydroxide.

\section{TABLE II.}

Amount of aqueous phase $=15$ c.c.

Amount of oil phase $=15$ c.c.

Amount of lead oxide $=$ about $4 \cdot 2$ grams per litre.

\begin{tabular}{|c|c|c|c|c|}
\hline \multicolumn{2}{|c|}{ Electrolyte. } & $\begin{array}{l}\text { Quantity in } \\
\text { gram-mols. } \\
\text { per cent. }\end{array}$ & $\begin{array}{l}\text { Type of } \\
\text { emulsion. }\end{array}$ & Stability. \\
\hline $\mathrm{KCl}$ & $\left\{\begin{array}{l}1 \\
2 \\
3\end{array}\right.$ & $\begin{array}{l}0.002 \\
0.004 \\
0.005\end{array}$ & $\begin{array}{c}\mathrm{W} \text { in } \mathrm{O} \\
,, \\
,\end{array}$ & Not very stable. \\
\hline $\mathrm{K}_{2} \mathrm{SO}_{4}$ & $\left\{\begin{array}{l}1 \\
2 \\
3\end{array}\right.$ & $\begin{array}{l}0 \cdot 003 \\
0 \cdot 0042 \\
0 \cdot 006\end{array}$ & ", & \\
\hline $\mathrm{Al}_{2}\left(\mathrm{SO}_{4}\right)_{3}$ & $\left\{\begin{array}{l}1 \\
2 \\
3\end{array}\right.$ & $\begin{array}{l}0 \cdot 001 \\
0 \cdot 003 \\
0 \cdot 006\end{array}$ & ", & \\
\hline $\mathrm{K}_{3} \mathrm{PO}_{4}$ & $\left\{\begin{array}{l}1 \\
2 \\
3\end{array}\right.$ & $\begin{array}{l}0.0021 \\
0.008 \\
0.009\end{array}$ & $\mathrm{O}$ in $\mathrm{W}$ & \\
\hline КОH & $\left\{\begin{array}{l}1 \\
2 \\
3\end{array}\right.$ & $\begin{array}{l}0.002 \\
0.004 \\
0.005\end{array}$ & $\begin{array}{l}W \text { in } O \\
O \text { in } W \\
, y\end{array}$ & Stable in all other cases \\
\hline
\end{tabular}

\section{Aluminium Hydroxide.}

The aluminium hydroxide was prepared by the action of ammonium hydroxide on a solution of pure aluminium sulphate. The moist precipitate was dialysed in parchment until the internal and the external water was neutral to litmus. This coagulum was made up to a litre and used as described in the case of zinc hydroxide. Some of the results are shown in Table III. 
BHATNAGAR : STUDIES IN EMULSIONS. PART III. 1763

\section{TABLE III.}

Amount of aqueous phase $=20$ c.c.

Amount of oil phase $=20$ c.c.

Amount of aluminium hydroxide $=$ about $3 \cdot 8$ grams per litre.

\begin{tabular}{|c|c|c|c|c|}
\hline \multicolumn{2}{|c|}{ Electrolyte. } & $\begin{array}{l}\text { Quantity in } \\
\text { gram-mols. } \\
\text { per cent. } \\
0.002\end{array}$ & $\begin{array}{l}\text { Type of } \\
\text { emulsion. }\end{array}$ & Stability. \\
\hline $\mathrm{KCl}$ & 1 & 0.002 & $\mathrm{~W}$ in $\mathrm{O}$ & Not very stable. \\
\hline nCA & $\left\{\begin{array}{l}2 \\
3\end{array}\right.$ & $\begin{array}{l}0.004 \\
0.005\end{array}$ & , & $"$ \\
\hline $\mathrm{K}_{2} \mathrm{SO}_{4}$ & $\left\{\begin{array}{l}1 \\
2 \\
3\end{array}\right.$ & $\begin{array}{l}0.002 \\
0.003 \\
0.005\end{array}$ & ", & ", \\
\hline $\mathrm{K}_{3} \mathrm{PO}_{4}$ & $\left\{\begin{array}{l}1 \\
2\end{array}\right.$ & $\begin{array}{l}0.001 \\
0.0035\end{array}$ & 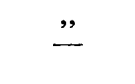 & $\begin{array}{l}\text { Tendency to separate } \\
\text { into two layers. }\end{array}$ \\
\hline $\mathrm{KOH}$ & $\begin{array}{l}3 \\
1 \\
2 \\
3\end{array}$ & $\begin{array}{l}0.004 \\
0.001 \\
0.0015 \\
0.002\end{array}$ & $O \overline{\text { in } W}$ & $\begin{array}{l}\text { Stable. } \\
\text { Tendency to separate. } \\
\text { Stable. } \\
\text {," }\end{array}$ \\
\hline
\end{tabular}

Casein.

The casein was a pure sample supplied by Messrs. Baird and Tatlock. A weighed quantity was dissolved in N/10-potassium hydroxide and gradually precipitated by acetic acid, the coagulum being then dialysed as in previous cases. The results obtained by casein suspensions when the casein was used dry and when precipitated as described were very nearly identical and therefore the results with the former alone are given.

\section{TABLE IV.}

Amount of aqueous phase $=20$ c.c.

Amount of oil phase $=20$ c.c.

Amount of casein per litre of suspension $=1.985$ grams.

\section{$\mathrm{KCl}$}

Electrolyte.

$\mathrm{K}_{2} \mathrm{SO}_{4}$

$\mathrm{Ba}\left(\mathrm{NO}_{3}\right)_{2}\left\{\begin{array}{l}1 \\ 2 \\ 3\end{array}\right.$

$\mathrm{Al}_{2}\left(\mathrm{SO}_{4}\right)_{3}\left\{\begin{array}{l}1 \\ 2 \\ 3\end{array}\right.$

$\mathrm{K}_{3} \mathrm{PO}_{4} \quad\left\{\begin{array}{l}1 \\ 2 \\ 3\end{array}\right.$

$\mathrm{Th}\left(\mathrm{NO}_{3}\right)_{4}\left\{\begin{array}{l}1 \\ 2 \\ 3\end{array}\right.$

$\mathrm{HCl} \quad\left\{\begin{array}{l}1 \\ 2 \\ 3\end{array}\right.$
Quantity in gram-mols. per cent.

0.005

$0 \cdot 005$

0.003

0.004

0.006

0.001

0.003

0.004

0.003

0.005

0.006

0.0001

0.00035

0.0005

0.0003

0.0004

0.00045
Type of emulsion.

$\mathrm{O}$ in $\mathrm{W}$

,

,

,

,

$\mathrm{W}$ in $\mathrm{O}$ ,

$\mathrm{O}$ in $\mathrm{W}$ ",

,

$\mathrm{W}$ in $\mathrm{O}$ $\Rightarrow$

$O$ in $W$

$\mathbf{W}$ in $\mathbf{O}$
Stability.

Stable.

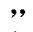

;,

,

$$
\text { , }
$$

Stable, though some water separates on agitation.

Stable.

,

,

Stable, water separating on agitation.

," 3 P

VOL. CXIX. 


\section{Rosin.}

The rosin used was the sample known as the "Seven Star Brand." The finely powdered material was shaken for several hours with a large quantity of water to remove any gummy substance which might have been added to it to increase its weight. After being filtered, the powdered rosin was dried in a current of hot air, dissolved in absolute alcohol, and recovered by evaporation of the solvents. The alcoholic solution was slightly acid, which is a well-known property of many of the pure rosins.

TABLE V.

Amount of aqueous phase $=20$ c.c.

Amount of oil phase $=20$ c.c.

Amount of rosin $=3$ grams per litre.

\begin{tabular}{|c|c|c|c|c|}
\hline \multicolumn{2}{|c|}{ Electrolyte. } & $\begin{array}{l}\text { Quantity in } \\
\text { gram-mols. } \\
\text { per cent. }\end{array}$ & $\begin{array}{l}\text { Type of } \\
\text { emulsion. }\end{array}$ & Stability \\
\hline $\mathrm{KCl}$ & $\left\{\begin{array}{l}1 \\
2 \\
3\end{array}\right.$ & $\begin{array}{l}0.002 \\
0.003 \\
0.006\end{array}$ & $\begin{array}{c}\mathrm{W} \text { in } \mathrm{O} \\
\Rightarrow, \\
\Rightarrow\end{array}$ & $\begin{array}{c}\text { Quite stable. } \\
,, \\
,,\end{array}$ \\
\hline $\mathrm{K}_{2} \mathrm{SO}_{4}$ & $\left\{\begin{array}{l}1 \\
2 \\
3\end{array}\right.$ & $\begin{array}{l}0.003 \\
0.004 \\
0.006\end{array}$ & ", & ", \\
\hline $\mathrm{K}_{3} \mathrm{PO}_{4}$ & $\left\{\begin{array}{l}1 \\
2 \\
3\end{array}\right.$ & $\begin{array}{l}0.003 \\
0.006 \\
0.008\end{array}$ & $\mathrm{O}$ in $\mathrm{W}$ & ", \\
\hline $\mathrm{KOH}$ & $\left\{\begin{array}{l}1 \\
2 \\
3\end{array}\right.$ & $\begin{array}{l}0.001 \\
0.002 \\
0.003\end{array}$ & $\begin{array}{c}W \text { in } O \\
O \text { in } W \\
, y\end{array}$ & ", \\
\hline
\end{tabular}

Discussion of Results.

From the results shown in Tables I-VI it is easily seen that aluminium hydroxide, zinc hydroxide, lead oxide, and rosin, prepared according to the methods described above and freed from alkali and alkaline salts like tripotassium phosphate, yield emulsions of the water-in-oil type; casein, lecithin, and egg-albumin yield emulsions of the reverse type. In the case of aluminium hydroxide, the emulsions are unstable in the region water-in-oil. The addition of a small quantity of potassium hydroxide, tripotassium phosphate, or sodium carbonate to the aqueous phase makes emulsions of the oil-in-water type quite stable, and the original, unstable water-in-oil type of emulsion can be reproduced by the addition of a small amount of an acid. Just before the point of complete inversion there is a tendency for the emulsions to go through a zone of instability, and in most cases, especially when the quantity of the emulsifying agent is large, this zone of 


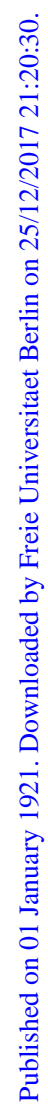

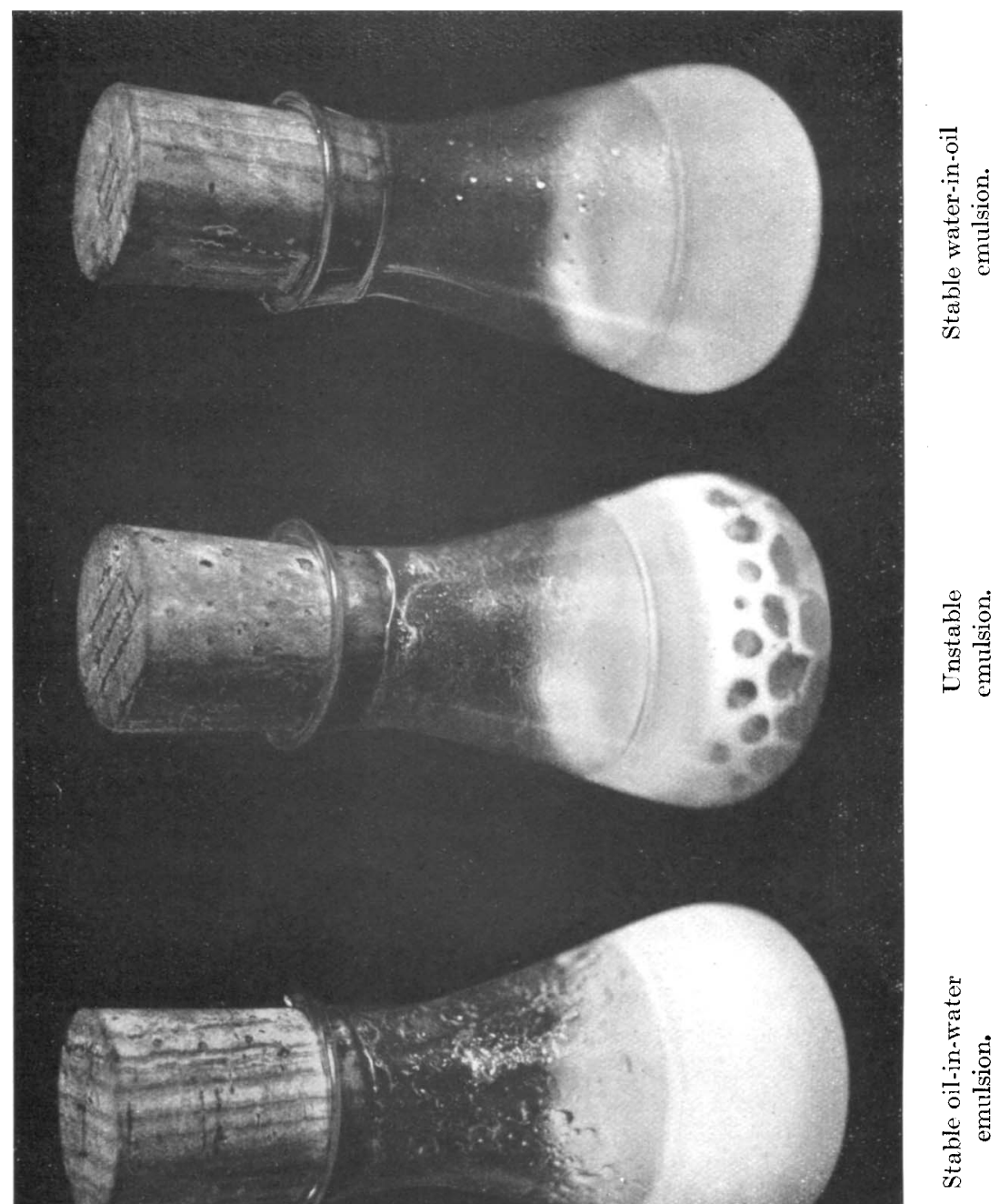

[T'o face $p .1765$, Trans. 
instability can be seen. Plate I, which represents the oil-in-water type, the unstable zone, and the water-in-oil type, is a photograph of emulsions prepared by using lead oxide as emulsifying agent, the reversing electrolyte employed being potassium hydroxide.

It is interesting to note that all emulsions described in this paper can be made to undergo a reversal of type by suitable electrolytes, and the following empirical rules appear to hold good:

1. An emulsion of water in oil can be transformed into one of oil in water by electrolytes having reactive anions like $\mathrm{OH}^{\prime}$ and $\mathrm{PO}_{4}{ }^{\prime \prime \prime}$.

2. An emulsion of oil in water can be transformed into the reverse type by electrolytes having reactive cations like $\mathrm{H}^{*}, \mathrm{Al}^{\cdots}$, $\mathrm{Fe}^{\cdots}{ }^{\cdots}$, and $\mathrm{Th}^{\cdots} \cdots$.

A somewhat similar conclusion has been drawn by Clowes $(J$. Physical Chem., 1916, 20, 407), who showed an intimate connexion between the effect of electrolytes on the permeability of soap films to water and the reversal of phases in emulsions. Employing a modification of Donnan's pipette, he obtained some interesting results, which showed that the protective ratios of various electrolytes on soap films are approximately logarithmic and correspond roughly with the precipitating effects exerted by the cations in question on soap dispersed in water. The fact that similar, approximately logarithmic, ratios have been observed during the study of the effects of bi- and ter-valent cations on a variety of colloidal and biological systems (Loeb and Beutner, ibid., 1913, 17,288 ) lends strong support to the view that we are dealing with adsorption phenomena. In the light of these results, Clowes made the significant classification of these antagonistic electrolytes into two groups. "The first consists of di- and tri-valent cations, etc., which possess a more readily adsorbed kation and promote the formation of the emulsion of water-in-oil; the second consists of alkalis, salts of monovalent kations and of di- and tri-valent anions which possess a more reactive and more readily adsorbed anion, and appear to exert the reverse effect of promoting the formation of oil dispersed in water."

According to Bancroft, the type of emulsion obtained depends on whether the emulsifying agent is more soluble in water or in oil. The introduction of the idea of solubility in one phase or the other is an extension of the rule, first put forward by Pickering, that the main factor determining the formation of one type or the other is whether the emulsifying agent is more easily wetted by the oil or by the water. The original view of Pickering is to be preferred; first, because the physical explanation of the phenomenon as given by Bancroft introduces certain complications into 
our ideas of interfacial tension, and it is by no means easy to understand the two interfacial tensions of a film formed by the concentration of the dissolved substance at the interface according to the Gibbs-Thomson law, and more especially so when the film is assumed to be freely permeable to at least one of the two phases of the emulsions; secondly, for the reason that some bivalent soaps like calcium oleate, barium linoleate, calcium linoleate and palmitate, barium oleate, and zinc stearate, etc., are almost as insoluble in kerosene oil and benzene as in water, and certain univalent soaps, like sodium and potassium oleates, stearates, and linoleates, are soluble in oils as.well as in water. Further, there are many substances which dissolve either in water or in oil and lower the surface tension and yet do not form emulsions. Donnan and Terroine, Mayer, Schaeffer (Compt. rend., 1908, 146, 484), and lately Fischer, Hooker, and Clayton (J. Soc. Chem. Ind., 1919, 38, 113T-118T) have pointed out that the emulsifying agent must be colloidal in nature, and it is probable that an explanation of the reversal of type by electrolytes is to be found in the nature of the adsorption by the colloidal surface films which envelop the globules. It is no doubt true that one may get some idea of the wetting power of a liquid by its property of dissolving a particular substance, but it is well known that the argument cannot be pushed too far, and many a substance, although insoluble in certain liquids, may yet be wetted by them. It is also well known that soaps are precipitated by the addition of univalent electrolytes, and in fact this action of sodium chloride has been taken advantage of in the technical manufacture of soap in the process of "salting out." It is very difficult to draw a hard and fast line between the effects of univalent electrolytes and of bi- and ter-valent electrolytes on soap solutions, as both of these are adsorption phenomena. On the solubility hypothesis, sodium chloride ought to be capable of changing the type as well as barium chloride. This is, however, contrary to all experience, and the multivalent ions alone are known to cause the reversal of type. There is thus a striking resemblance between these effects of the electrolytes on the reversal of type and the reversal of charge on the colloid emulsifier, and it lends strong support to the view, first put forward by Clowes, that the antagonistic effects of electrolytes are attributable to a balance between the cations on the one hand, and the anions on the other, adsorbed by or reacting with the constituents of the surface film or membrane.

The classical researches of Loeb (Biochem. Zeitsch., 1912, 39, $127 ; 1913,51,88)$ on the effects of reactive cationic electrolytes on lipoids, lecithin, protein, and casein show that they react with them so as to form water-insoluble salts oppositely charged to the 
original lipoids. In explaining the analogous behaviour of certain biological and protoplasmic systems, Mines (J. Physiol., 1912, 43, 467), Loeb and Beutner (loc. cit.), and Clark (J. Physiol., 1913, $47,66)$ have emphasised the importance of both these effects.

The data on the question of the formation of the water-in-oil and the oil-in-water emulsions and their transformation into one form or the other are restricted (1) to results on various soaps by Newman, Clowes, Briggs, and Bhatnagar, and (2) to the work of Pickering and the results embodied in this paper. For the sake of closer comparison, a table of the emulsifying agents so far tried and of the electrolytes which reverse the type is shown below.

\section{TABLE VI.}

\begin{tabular}{|c|c|c|c|}
\hline $\begin{array}{l}\text { Emulsifying } \\
\text { agent. }\end{array}$ & $\begin{array}{c}\text { Reversing electrolyte : } \\
\text { Salts of }\end{array}$ & $\begin{array}{l}\text { Type of } \\
\text { emulsion. }\end{array}$ & $\begin{array}{l}\text { Nature of the ad- } \\
\text { sorption com- } \\
\text { pounds; + repre- } \\
\text { sents excess of } \\
\text { adsorption of } \\
\text { positive ions, - } \\
\text { represents excess } \\
\text { of adsorption of } \\
\text { negative ions. }\end{array}$ \\
\hline Sodium oleate & $\begin{array}{l}\mathrm{Ba}, \mathrm{Ca}, \mathrm{Sr}, \mathrm{Fe}, \mathrm{Cr}, \mathrm{Al}, \\
\mathrm{Cu}, \mathrm{Zn}, \mathrm{Ni}\end{array}$ & $O$ in $W$ & + \\
\hline Carbon & $\mathrm{KOH}, \mathrm{K}_{3} \mathrm{PO}_{4}$ & $W$ in $O$ & - \\
\hline $\begin{array}{l}\text { Casein } \\
\text { Albumin }\end{array}$ & $\mathrm{Al}, \mathrm{Fe}, \mathrm{Th}, \mathrm{H}$ & $O$ in $W$ & + \\
\hline Zinc hydroxide & $\mathrm{KOH}, \mathrm{K}_{3} \mathrm{PO}_{4}$ & $\mathrm{~W}$ in $\mathrm{O}$ & - \\
\hline $\begin{array}{l}\text { Zinc hydroxide } \\
\text { (alkaline) }\end{array}$ & Al, $\mathrm{Th}, \mathrm{H}$ & $O$ in $W$ & + \\
\hline $\begin{array}{l}\text { Aluminium } \\
\text { hydroxide }\end{array}$ & $\mathrm{KOH}, \mathrm{K}_{3} \mathrm{PO}_{4}$ & $\mathrm{~W}$ in $\mathrm{O}$ & - \\
\hline Lead oxide & $\mathrm{KOH}$ & , & - \\
\hline Rosin & $\mathrm{K}_{3} \mathrm{PO}_{4}, \mathrm{KOH}$ &, & - \\
\hline Lecithin & $\mathrm{Al}, \mathrm{Fe}, \mathrm{Th}$ & $O$ in $W$ & + \\
\hline Univalent soaps & $\begin{array}{l}\text { Bivalent and tervalent } \\
\text { metals }\end{array}$ &, & + \\
\hline
\end{tabular}

From a close study of the data on the reversal of type in emulsions, it is easily seen that the effects of the electrolytes on the surface film of the globules in emulsions are precisely similar to those on lipoids and protoplasm (Loeb and Osterhout, loc. cit.). Substances like tripotassium phosphate and potassium hydroxide have a decided effect on the wetting property of zinc, lead, and aluminium hydroxides, as well as on their surface potential, and a rational theory of emulsification should be capable of including and explaining the facts emphasised here. Wetting power is considered to be connected with interfacial tension, and therefore the two vital factors constituting a complete theory of the reversal of phases will be: ( 1 ) the nature of the charge on the emulsifying agent, and (2) its interfacial tension relations with the two phases. Unfortunately, our knowledge of the interfacial tension between 
solids and liquids is very limited, and for the present the entire data on the reversal of type are in agreement with the empirical rule "that all emulsifying agents having an excess of negative ions adsorbed on them and wetted by water will yield oil-in-water emulsions, whilst those having an excess of adsorbed positive ions and wetted by oil will give water-in-oil emulsions."

It is to be noted that emulsions prepared by gelatin and saponin do not undergo the reversal of type. Cataphoresis experiments on these emulsions show that the addition of bi- and ter-valent electrolytes changes the charge on the oil particles themselves. This is directly opposite to what happens in the case of soaps and casein. In these cases, owing to a complex chemico-adsorption process, the multivalent ions are almost wholly used up by the surface film, and the original negative charge on the oil is not disturbed. The protective film, having adsorbed; say, multivalent cations, is capable of protecting only similarly charged particles, a fact well known in colloidal chemistry. The positive particles in this case are water globules, and it is these particles which are now protected by the adsorbed surface film.

\section{Summary.}

1. The effects of various electrolytes on emulsions prepared by the use of zinc hydroxide, aluminium hydroxide, lead oxide, casein, rosin, and egg-albumin as emulsifying agents have been studied.

2. Univalent electrolytes are incapable of reversing the type of soap emulsions, even although they throw out the soap from solution.

3. An excess of adsorbed positive ions on the surface membrane leads to the formation of the water-in-oil type of emulsion. The reverse type is produced by the adsorption of negative ions.

4. All emulsions, whether prepared by soluble emulsifiers such as soaps or by insoluble ones such as zinc hydroxide, follow the empirical rule first suggested by Clowes.

5. Evidence has been accumulated which favours the view that the relative wetting power of the two phases with respect to the emulsifying agent and the surface potential of the membrane between them are the two main factors governing the process of emulsification, and that the reversal of phases in emulsions by electrolytes is brought about by the changes produced in the surface membrane with regard to either or both of these two factors.

The author takes this opportunity of thanking Professor F. G. 
DESCRIPTIONS OF PYRIDINE, ETC., DERIVATIVES. 1769

Donnan, F.R.S., for his helpful criticism and suggestions. His thanks are also due to Mr. H. I. Higson for taking some photographs of the emulsions and to his friends, Dr. J. C. Ghosh and Mr. J. N. Mukherjee.

Chemtcal Laboratory,

UNIVERSity COLlege, London, W.C.1.

[Received, August 8th, 1921.] 